\title{
BEHAVIOUR OF ULTRA-HIGH PERFORMANCE FIBRE REINFORCED CONCRETE BEAM-COLUMN JOINT UNDER CYCLIC LOADING
}

\author{
Charles K.S. Moy ${ }^{*}$, Jun Xia ${ }^{*}$, Chee Chin ${ }^{*}$, Jianzhong Liu ${ }^{* *}$ \\ * Xi'an Jiaotong-Liverpool University, Dept. Civil Engineering, China \\ e-mails: charles.loo@xjtlu.edu.cn, jun.xia@xjtlu.edu.cnmailto:,Chee.Chin@xjtlu.edu.cn \\ ${ }^{* *}$ Jiangsu Sobute New Materials Co. Ltd, China \\ e-mail: ljz@cnjsjk.cn
}

\begin{abstract}
Ultra-high performance fibre reinforced concrete (UHPFRC) has very high compressive strength up to $200 \mathrm{MPa}$ and exhibits strain hardening effects under flexural loading. The bond strength between UHPFRC and steel reinforcement is much better than the normal strength concrete. Therefore, there is a potential to use UHPFRC material at the beam-column joint region to reduce the congestion of reinforcement as well as to improve the seismic resistance of the structure. In this pilot study, the beam column joints made of normal strength concrete and UHPFRC were tested under lateral cyclic loading up to failure using a 500 tonne capacity computer control servo hydraulic machine. The specimen with normal strength concrete failed at the joint region while the specimen with UHPFRC material failed due to yielding of the rebars in the beam sections near the column face and no obvious cracks were observed at the joint area. The specimens with UHPFRC as joint material exhibited higher initial lateral stiffness and achieved slightly higher ultimate load capacity than the specimen with normal strength concrete.
\end{abstract}

Keywords: Push-over, Hysteretic curve, Cracking pattern

\section{INTRODUCTION}

Adoption of ultra-high performance fibre reinforced concrete (UHFRPC) in bridges, building and infrastructure has been reported previously [1]. Due to its high strength, self-consolidation performance, and excellent durability, UHPFRC material is now getting popularities in the construction industry $[2,3]$. Moreover, the addition of micro steel fibres, which bond tightly with concrete matrix, provide good ductility and lead to strain hardening effects under flexural bending [4]. Meanwhile, the high embodied energy, material cost, and environmental impact, for example carbon dioxide emission, over the life cycle [5] limits the wide application of the material. Considering the sustainability requirement, the effective use of UHPFRC material becomes an important issue.

\section{MATERIAL AND SPECIMEN DESIGN}

The mix design for the normal strength concrete is listed in the following Table 1. The ultra-high performance fibre reinforced concrete used in this research is a premix product commercially available. $2 \%$ volume fraction of micro fibre was used in the mix design. Those fibres are approximately $13 \mathrm{~mm}$ long and $0.2 \mathrm{~mm}$ in diameter, which gives an aspect ratio of 65 .

Table 1. Mix design of normal strength concrete $\left(\mathrm{kg} / \mathrm{m}^{3}\right)$

\begin{tabular}{ccccc}
\hline Cement & Water & $\begin{array}{c}\text { Fine } \\
\text { aggregate }\end{array}$ & $\begin{array}{c}10 \mathrm{~mm} \\
\text { coarse } \\
\text { aggregate }\end{array}$ & $\begin{array}{c}20 \mathrm{~mm} \\
\text { coarse } \\
\text { aggregate }\end{array}$ \\
\hline 490 & 195 & 470 & 400 & 805 \\
\hline
\end{tabular}


The beam-column joint specimen and reinforcement details are shown in Figure 1. Two specimens were designed with the identical geometry and reinforcement layout with the only difference in the concrete material used at the joint region as indicated in Figure 1. The detailed configuration of the steel reinforcement at the joint region as tied can be found in Figure 2a). After casting, both specimens were sprayed with curing agents and covered by the plastic sheet until the day of testing (31 days after casting) as shown in Figure 2b). Concrete cylinders and cubes were prepared and cured under the same condition as the specimens for both type of concrete materials prior to strength tests.

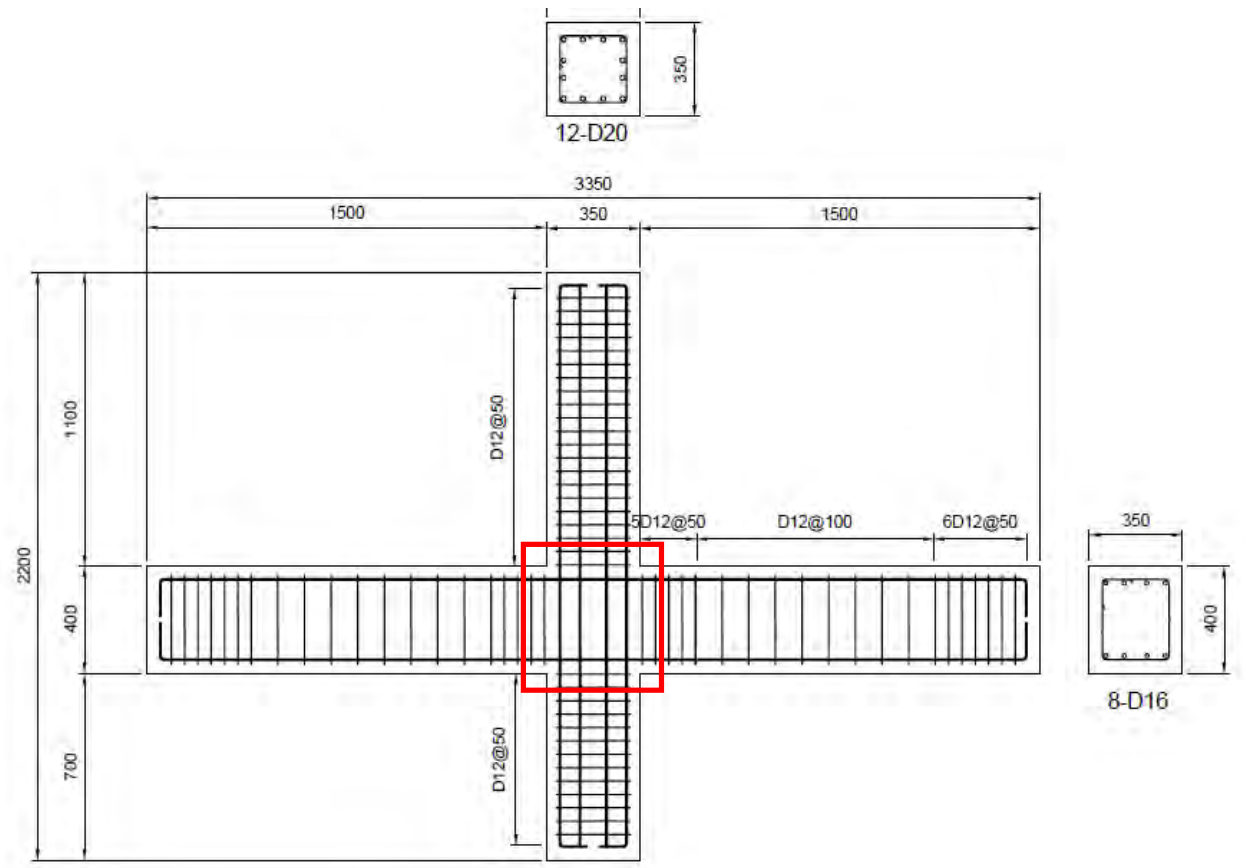

Figure 1. Geometry and reinforcing scheme for beam-column joint specimens (Dimension: mm)
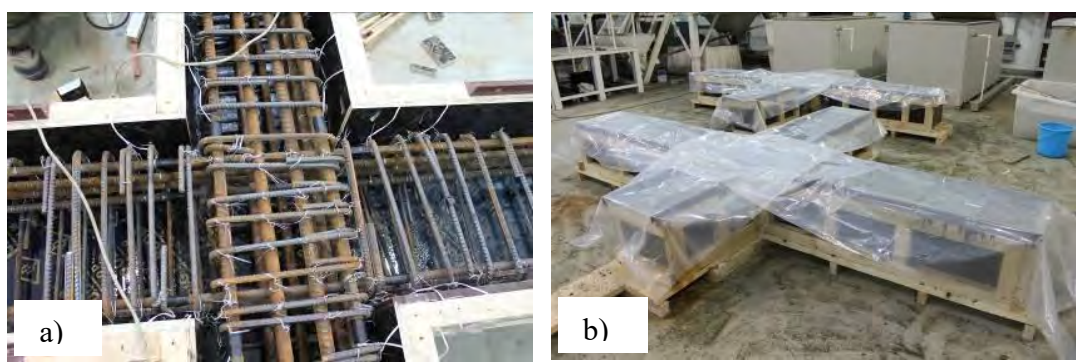

Figure 2. Specimens preparation: a) Details of the reinforcement at the joint region; b) Curing of the specimens. 


\section{EXPERIMENTAL PROCEDURES}

The beam-column joint test was performed using the 500 tonne loading system in the structures lab at Xi'an Jiaotong-Liverpool University as shown in Figure 3a). The specimens were loaded under constant vertical loading of $200 \mathrm{kN}$ and then lateral displacement was enforced from the top-side of the column following target history shown in Figure 3b). The lateral displacement was controlled with three complete cycles for each displacement target level. Displacements and strains of the reinforcement at the joint region were measured using the data acquisition system in real time with a frequency of $1 \mathrm{~Hz}$ and the cracks were observed after completing each target displacement.
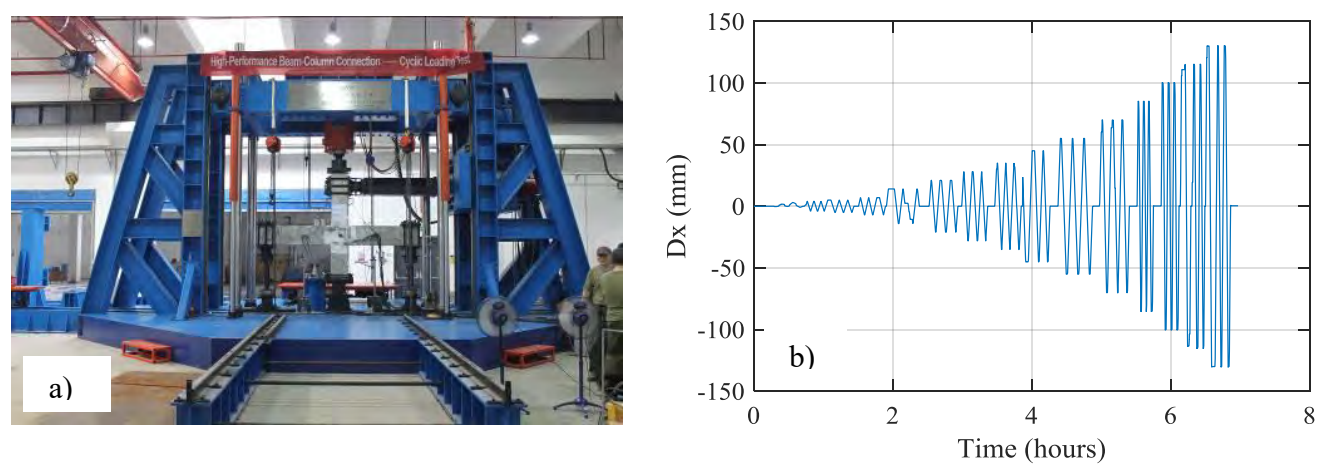

Figure 3. Specimens under Testing: a) Loading configuration; b) Target (Dx) History.

\section{TESTING RESULTS}

The compressive strength obtained from $150 \mathrm{~mm}$ x $150 \mathrm{~mm} \times 150 \mathrm{~mm}$ cubes (for normal strength concrete) and $100 \mathrm{~mm} \times 100 \mathrm{~mm} \times 100 \mathrm{~mm}$ cubes (for UHPFRC) were $52 \mathrm{MPa}$ and $136 \mathrm{MPa}$, respectively. The hysteretic curves for both systems are shown in Figure 4a), with the responses for the first three cycles shown in Figure 4b). It was found that Specimen S2 exhibits higher stiffness than specimen S1 in the initial cycles and generally provided slightly better ductility reaching around $200 \mathrm{kN}$ lateral resistance with lateral deformation in excess of $70 \mathrm{~mm}$. The energy dissipation for specimen S2 was also better than S1. Both specimens initiated the nonlinear responses due to the yielding of the rebars in the beam. However, specimen S1 suffered from quick stiffness loss due to the cracking and spalling of concrete at the joint region as shown in Figure 5a) while for specimen S2, the cracks were observed at the top and bottom of the beam close to the joint region as shown in Figure 5b). No obvious cracks were observed in the joint region for the latter, where the ultra-high performance fibre reinforced concrete was used. 

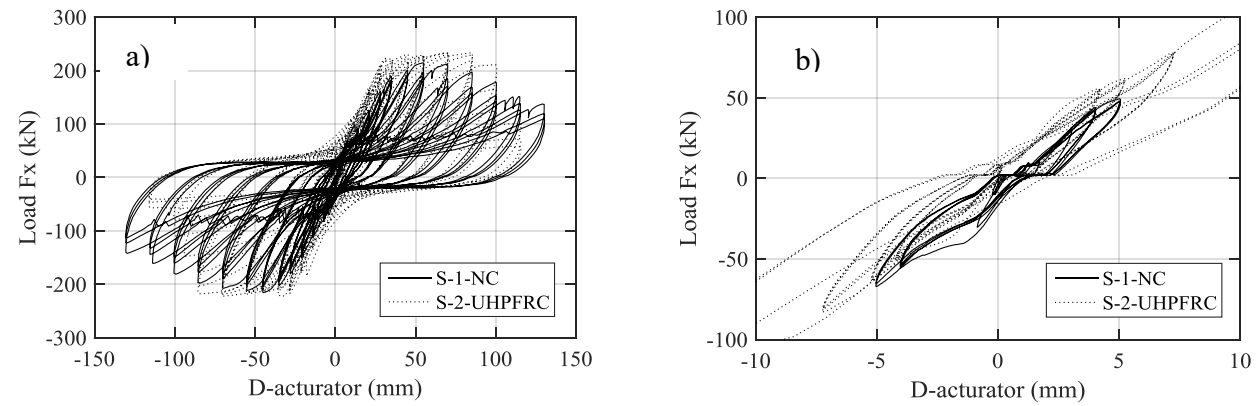

Figure 4. Test Results: a) Complete hysteretic curve, b) First three cycles.
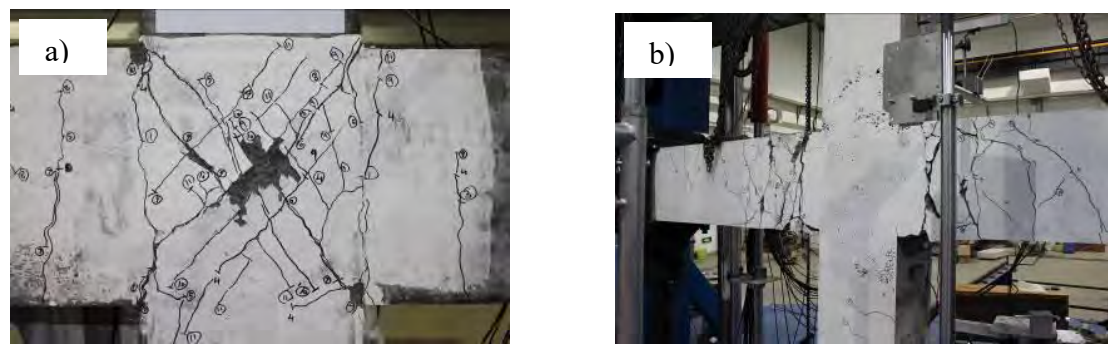

Figure 5. Test Results: a) joint cracking and spalling for S1, b) Cracking outside of joint region for S2

It was also deduced that the rebar embedded in UHPFRC material was fully restrained by the dense concrete material based on the comparison of strain readings from the rebars at beam and column close to the joint region as shown in Figure 6. The strain of rebar in both beam and column were all much larger than the corresponding values from S2.
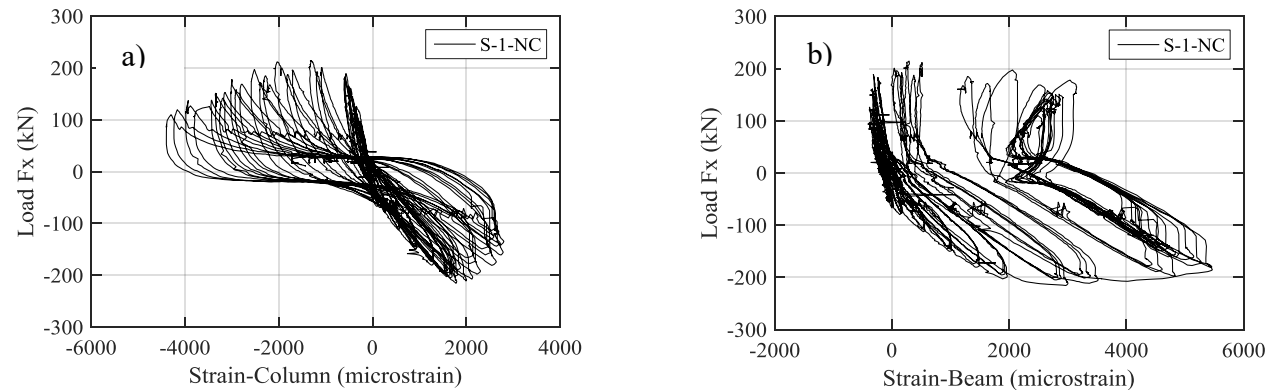

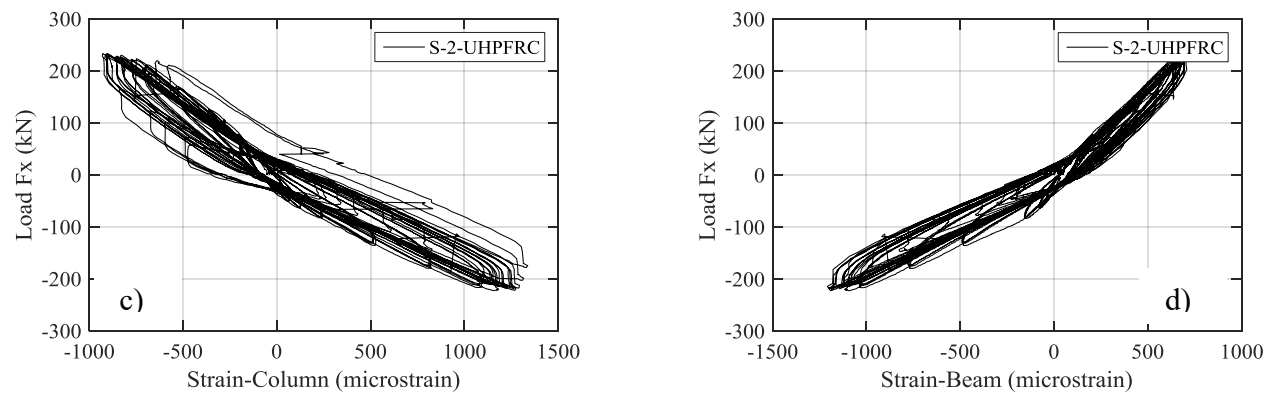

Figure 6. Test Results: a) strain of rebar in column for S1, b) strain of rebar in beam for S1, c) strain of rebar in column for S2, d) strain of rebar in beam for S2;

Based on the reverse-cyclic loading experiment results of two beam-column joint specimens, it was found that the utilization of ultra-high performance fibre reinforced concrete material in the joint region can help prevent the cracking and spalling of concrete. The rebars were fully restrained due to the high strength of concrete and good bond strength achieved.

\section{CONCLUSION}

This study investigated how the incorporation of UHPFRC at the beam-to-column joint may improve the failure mode under cyclic loading for possible application under earthquake loading conditions. The strengthened joint with UHPFRC (S2) was able to reduce significantly the cracks at the joint region and shift the plastic hinge to the beam region which is desirable for seismic designs. Although the peak lateral load capacity achieved by both S1 and S2 specimens are not significantly different, the specimen with UHPFRC (S2) failed in a more identifiable manner with plastic hinge formed near the interface between the two concrete materials.

In addition, the strain of the reinforcement of the UHPFRC sample remained in the linear elastic range as compared to the sample with normal concrete which resulted in plastic response. Hence, the reinforcement at the joint for specimen S2 could potentially be reduced to make more efficient use of the two materials. This would require further investigation.

\section{REFERENCES}

[1] Resplendino, Jacques, and Francois Toulemonde. Designing and Building with UHPFRC. 2011. Wiley-ISTE.

[2] Rossi, P. "Development of New Cement Composite Materials for Construction." Proceedings of the Institution of Mechanical Engineers --Part L --Journal of Materials: Design \& Applications 219.1 (2005): 67-74.

[3] Hassan, A. M. T., S. W. Jones, and G. H. Mahmud. "Experimental Test Methods to Determine the Uniaxial Tensile and Compressive Behaviour of Ultra High-Performance Fibre Reinforced Concrete (UHPFRC)." Construction and Building Materials. (2012): 874-82.

[4] Yoo DY, Banthia N, Yoon YS. Predicting the flexural behavior of ultra-high-performance fiberreinforced concrete. Cement and Concrete Composites. 2016;74:71-87.

[5] Graybeal, Benjamin A. Material Property Characterization of Ultra-High Performance Concrete: Federal Highway Administration, 2006. 